\title{
Teachers' Perspectives Towards Professional Training Programs at Arba Minch University, Ethiopia: Focus in Higher Diploma Program Training
}

\author{
Zelalem Zekarias Oliso \\ Arba Minch University, Ethiopia
}

\begin{abstract}
The purpose of this qualitative inquiry was to investigate teachers' perception towards Higher Diploma Program (HDP) training. To this end, qualitative research approach was employed with semi-structured interviews and focus group discussion (FGD as main data gathering tool). The participants for this study were purposively selected. Semi-structured interview was conducted with HDP Coordinators and Higher Diploma Leaders and Tutors. Following interview, focus group discussion was conducted with Higher Diploma Candidates. The data gathered were analyzed using case study design methods. Major themes and sub themes are described by inductive processes based on the grounded theory method. The finding of this study revealed that teachers have positive perception towards HDP training program because it improves teachers' professional knowledge. However, the study participants throughout in the interview and focus group discussion session noticed that HDP training lacks incentive, follow up and support from the side of the university. It was therefore recommended that the university should improve the incentive mechanisms as well as follow up and support for the success of the program.
\end{abstract}

Keywords: Professional Training, Perspective; Higher Diploma Program; Profession; Quality Teaching

DOI: $10.7176 / \mathrm{JEP} / 12-4-05$

Publication date: February $28^{\text {th }} 2021$

\section{INTRODOCTION}

Teachers are the main factor contributing to quality education. The nation can be developed from the responsibility of the teacher (Boonmak et al., 2015). Reflective of that belief, in the Ethiopian context, teachers are required to have professional competency, and participate in continuous professional development (CPD), in order to learn new knowledge to apply in the classroom (MoE, 2010). According to New Education and Training Policy (NETP) of Ethiopia (1994), teachers starting from kindergarten to higher education, are required to have the necessary teaching qualification and competency in the media of instruction, through pre-service and inservice training. Those who educate higher education students must themselves be of high quality, be highly competent in order to produce better skilled manpower.

Higher Diploma Program (HDP) is one of professional training programs that put in place by the MoE to improve the quality of Ethiopian higher education. It is a licensing training Program that is aimed at developing the skills and professionalism of teacher educators (UNESCO, 2007). The HDP introduced in Ethiopia since 2004G.C. It is offered to graduate assistants, lecturers, and professors, all receiving the same kind of training (Demewoz, 2016). Its overall purpose is to improve the skills and professionalism of higher education teachers. To this end, the training of HDP comprises the following four major themes: reflective teacher educator, managing learning, action research, and school placement. The program is a government initiative and the control is highly centralized (Adula, 2008). The program is designed for one academic year to be carried out in all government teacher education colleges and public universities (MoE, 2006).

At Arba Minch University (AMU), the HDP started since 1999E.C or 2006/07 academic year. The Ethiopian Federal Ministry of Education (MoE) has mandated AMU, with the responsibility of moderating for four cluster institutions, i.e. Hosanna College of Teachers' Education, Arba Minch College of Teachers' Education, Wolaita Soddo University \& Wachamo University. Currently, HDP is being carried in four AMU campuses and run by the School of Pedagogical and Behavioral Sciences. According to School of Pedagogical and Behavioral Sciences information, from the total of 1,450 local instructors, only 723 (645 male and 78 female) teachers are licensed with HDP certificate in ten consecutive years starting from 2006/07 G.C to 2015/16 G.C.

\section{Problem Statement}

Teachers are responsible for communicating effectively all curriculum content. Without high levels of competency, transmission of knowledge, skills and values was being weak. The government therefore provided support to better facilitate this transition by improving qualification processes and standards (pre-service training), enriching CPD and strengthening supervision processes (in-service training) (MoE,2005). And an extensive study conducted with MoE in (2002) covering the overall education system of Ethiopia and teacher education system overhaul (TESO) in particular revealed that Ethiopian teachers failed to implement active 
learning method. The first action; therefore, taken by TESO was designing curriculum material in modular approach following the educational policy of Ethiopia that aimed at developing the culture of active learning and problem-solving approach of instruction. In order to implement the material, HDP was designed and is being provided to teacher educators (Adula, 2008).

Despite the substantial amount of research that has been conducted on HDP, current literature discusses on the implementation, effectiveness of the program and application of the HDP training skills in the classroom instruction. This study was designed to provide insight into teacher's perception towards HDP. I am interested in conducting research on this area, because of two major reasons. First, this training program is a compulsory training for all university instructors according to MoE information. The HDP was introduced in 2004 as a compulsory qualification for all teacher educators (MoE, 2003). Currentyl, at Arba Minch University, there are 1,450 local and 96 expatriate instructors teaching in the university. However, from the total of 1,450 local instructors, only 723 are licensed with HDP certificate in ten consecutive years starting from 2006/07-2015/16 as mentioned earlier. According to this information, the numbers of HDP graduates are worryingly much fewer as compared to the total number of instructors in the university.

Secondly, for the last two years, I was Higher Diploma Program Leader (HDL) in Arba Minch University. During my stay with instructors as HDL, I observed that teachers were reluctant to involve in different group, discusses issues and they raise the value of HDP training. Accordingly, considering my first-hand experience as HDL at Arba Minch University and low participation of teachers in the HDP training, I identified the topic as an important area of investigation for the clarification of teachers' perception, the opportunities of the program for their professional development and exploring the situation of HDP in the context of our education system in general and the university's academic development settings in particular. To provide focus for this research, the following questions were developed:

1. What are teachers' perceptions towards HDP training?

2. What is necessary knowledge, skills and attitude gained from HDP training?

3. What are the challenges encountering the smooth running of the HDP training?

\section{MATHERIALS AND METHODS}

\section{Research Design}

In this study, a qualitative case study design was used, because it is important to investigate the problem in-depth in one or more real-life settings (case sites) over an extended period of time (Bhattacherjee, 2012).

\section{Study Participants \\ Total Population}

According to the School of Pedagogical and Behavioral Sciences information, in four campuses, there are eight Higher Diploma Program Leaders (HDLs) and Higher Diploma Program Tutors (HDTs), One Higher Diploma Program Coordinator (HDC), one Dean, School of Pedagogical and Behavioral Sciences and one hundred seventy seven HDP Candidates are now attending the training. Of these candidates, one hundred fifty nine candidates are male candidates and eighteen candidates are female candidates. The following table summarizes the total number of candidates who are attending the HDP training at Arba Minch University in the 2009 E.C.

Table 3.1: HDP Candidates who are attending the training at AMU in the Year 2009 E.C or 2017 G.C.

\begin{tabular}{|l|l|l|l|}
\hline Campus & Male & Female & Total \\
\hline Main Campus & 65 & 8 & 73 \\
\hline Chamo Campus & 29 & 7 & 36 \\
\hline \multirow{2}{*}{$\begin{array}{l}\text { Abaya Campus } \\
\text { Grand Total }\end{array}$} & 27 & 1 & 28 \\
\cline { 2 - 4 } & 159 & 2 & 40 \\
\hline
\end{tabular}

Source: AMU, School of Pedagogical and Behavioral Sciences

\section{Sampling Technique}

The participants for this study were chosen via purposeful sampling technique from the identified university. In purposeful sampling, researchers intentionally select individuals and sites to learn or understand the central phenomenon (Cresswell, 2012).

\section{Procedures of Participant Recruitment for the Study}

The participants of this study were recruited using the following procedure:

Higher Diploma Candidates: from four campuses, candidates were primarily selected based on their interest. To be included in the study, they are also expected to have at least two years of teaching experience and be currently involved in a Higher Diploma Program because teachers with two or more years of teaching 
experience in the selected university are assumed to have experience in the professional development programs.

Higher Diploma Leaders (HDLs): All HDLs/HDTs took part in this study, because they have frequent interaction with candidates at least two times in a week and they are assumed to have an understanding about the perception of the candidate toward the program.

Facilitators of the Program: Facilitators include people such as Higher Diploma Coordinator (HDC), and Dean, School of Pedagogical and Behavioral Sciences were selected. They have ample experience in teaching as well as coordinating and facilitating the program.

\section{Methods of Data Collections \&Procedures}

In this study, two types of data collection methods were employed; interview and focus group. For the purpose of this study, semi-structured interview was prepared, because in semi-structured interview, the interviewer is free to conduct the conversation as he/she thinks fit (Corbetta, 2003). The interview was conducted with two male facilitators (one Higher Diploma Coordinator (HDC) and one Dean, School of Pedagogical and Behavioral Sciences), and four male leaders/tutors. During the interview session, I took note and record the interview response via tape recorder in order to reduce the loss of audio information. And the interview session last from one to two hours, including breaks and that was done as per the suggestion of Mack et.al (2005) who notes indepth interviews should last from one to two hours.

Following the interview, FGD was employed with HDP Candidates as 'focus groups are used for generating information on collective views, and the meanings that lie behind those views" (Gill, 2008 p.293). For the purpose of FGD, eight participants from HDP Candidates were selected. And their sitting arrangement was in a circular manner to face each other in discussion. Circular sitting enables all group members to face each other, which is crucial for establishing the interactive group dynamics that are central to a focus group discussion (Hennink, 2007). To facilitate the FGD, I assigned two department heads from the department of pedagogy and psychology as moderator and note-taker as per the suggestion of Mack et. al's " focus groups work best is conducted by two researchers, often called facilitators. One person acts as the moderator of the discussion and the other is the note-taker" (Mack et.al, 2005 p.68). I was acting as assistant and took detail, note in addition to note- taker information in order to reduce information gap. In order to maintain confidentiality in the focus group, I implemented name substitution after the FGD session.

\section{Method of Data Analysis}

In this study, I employed qualitative aspect of data analysis. Initially, I read the interview and focus group transcripts thoroughly to gain a sense of the data and to evaluate the data without bias. I continued this holistic evaluation of the data multiple times, and assigned labels for emerging themes. I then organized the emerging themes into the major themes and sub themes. Finally, the emerged major themes and sub themes were described in the inductive process using the grounded theory method. The general inductive process can allow the researchers to uncover the most dominant themes from the data (Benes et.al, 2016).

\section{RESULTS AND DISCUSSIONS}

In this part, the results and discussions of this study are provided. A detailed discussion summarizes the results in relation to each of the corresponding themes as they associated with the research questions. In-depth descriptions with data from the focus group discussion and interviews are presented next.

\section{HDP Candidates Perception Towards HDP Training}

Participants reflect on the various benefits they gain from taking part in HDP. In addition, to gain some methodological skills, participants underline that it creates a forum for learning from one another;

My perception towards HDP training is positive," says one participant, "because it is a big tool for teachers in order to improve their professional knowledge on how to teach the learners. In HDP training program, we share experience with each other and this experience has its own role in the classroom instruction (Gebaba, FGD Participant 1).

Kebede, is another HDP candidate who has further explained how HDP training changed his previous perception towards HDP training:

Before I engaged in HDP training, I was not very interested towards the training. As education graduate, I always wondered if I could learn anything new from this training. After I participated in HDP training, I developed a positive attitude towards the HDP training, because I acquired necessary practical, professional knowledge on different methods of teaching, assessment methods, ways of implementing active learning methods in the large class size etc. (Male, FGD Participant, 2).

On the other hand, a few HDP Candidates from education graduates reported that the perception of the candidates from applied graduates and education graduates are not similar. That is because applied graduates consider the content of the HDP module as vital for their professional development, whereas education graduates 
consider the contents of the HDP module as repetition of the undergraduate courses. However, many of HDP Candidates of both education graduates and applied graduates discussed that undergraduate pedagogical courses are more theoretical, but HDP training contents are more of a practical and engage teachers in practical activity that they will apply in the classroom instruction. The main principle of HDP training is sharing, discussing, and practicing. Their conception is consistent with MoE's intention about the program; HDP program has been intended to provide teachers with a practical knowledge to support them as effective teachers and reflective practitioners with enhanced professional status (MoE, 2003).

In addition, the HDLs/HDTs in an interview sessions strengthened the importance of professional development programs for teachers. Abate (interview participant 8), explained the representative of others view about professional training: "the opposite of learning is forgetting. Teaching is a profession. Hence, a profession always needs training. HDLs and HDTs felt that though HDP module content and undergraduate pedagogical course contents are completelty different, the teachers need to update his/her knowledge". As stated in the OECD (2009), no matter how good pre-service training for teachers is, it cannot be expected to prepare teachers for all the challenges they will face throughout their careers without in-service trainings. In general, from the above information, we can understand that candidates have a positive attitude towards HDP program, even though there is a little discrepancy between education and applied graduates.

\section{Professional Knowledge Acquired from HDP Training}

HDP candidates were asked to describe and discuss the necessary professional knowledge, skills and attitude acquired from HDP training. They reported that they have acquired professional knowledge from this training program. As they mentioned, they have developed necessary professional knowledge, skills and attitudes in the following major areas of instructional process: Instructional Phase, Reflection, Collaborative Work, and Action Research. These four aspects of professional knowledge, skills and attitudes acquired from HDP training are discussed with relative detail below.

\section{Instructional Phase}

Many of HDP Candidates reflected that before HDP training, they face challenges in the following instructional phases: introduction, presentation, conclusion and evaluation while teaching. They reported that after HDP training, they have improved this problem in instructional phases. One of the HDP Candidates in FGD session has explained how HDP training improved his professional knowledge in instructional phase:

Before I engaged in HDP training, I face many challenges in applying instructional phases properly especially in introduction part. I start the session without introducing the instructional objectives. But after HDP training, I began with explanations to the learners about the instructional objectives (Male, FGD Participant, 2).

Aster, is another HDP Candidate has shared similar thoughts in a FGD session on how HDP training improved her knowledge on instructional. Her remarks could be considered as representative of other views:

I have shown some improvements in raising discussion questions for the class. Before taking HDP training, I used to raise questions randomly I mean questions which couldn't consider the learners' capacity. So, some students reflect their point of view of the raised questions. But my HDP training, I intentionally prepare questions before class based on learners' capacity. That way, I have been able encourage students to participate in class discussions and that has helped me to increase the participation of low achieving students (Female, FGD Participant, 8).

\section{Reflection}

Majority of HDP Candidates in this study reported that they have acquired necessary professional knowledge on how to be a reflective teacher. They felt that the reflective teacher plays a significant role in improving instructional process. Abebech (Participant 4), one of HDP Candidates in FGD session explained how she improved her professional knowledge regarding reflection: "I have acquired necessary professional knowledge on how to be reflective teacher. Instructional process need reflective teacher: what is the needs and interest of my students and how can I respond according their needs."

The most effective teachers are those who think about their practice, those who try to improve their practice through careful planning and evaluation, and those who focus on the needs of the learners. They are committed to reflective practice, continuing professional development and constantly trying to improve (MoE, 2011 p.15).

\section{Collaborative Work}

Many of HDP Candidates explained that in each HDP training session, they share experiences with each other because HDP training encourages collaborative work. One of the HDP candidates in FGD session explained how collaborative work improved his professional knowledge: 
HDP training gives an opportunity for candidates to share experiences with one another, because HDP Candidates are from different backgrounds and field of specializations. Candidates raise one issue from different perspectives or point of views. Adequate time is let for candidates to reflect their own point of view of the raised issue. This experience sharing has its own role in the improvement of classroom instruction (Male, FGD Participant 7).

His observation is consistent with Tate's reflection about effective professional program; effective professional development is active and engages teachers in problem solving scenarios, experience sharing and discussion (Tate, 2009).

\section{Action Research}

All HDP Candidates in this study reported that their knowledge of conducting action research is improved than before. HDP candidates are of the opinion that conducting action research in teaching learning process is playing a significant role for teachers to understand the challenges that they may face in the instructional process. Abebayehu, "before HDP training," says one focus group discussant;

I have little knowledge about the concept of action research. But after training of action research in a HDP training session, I have acquired necessary knowledge on how to conduct action research and what makes action research different from other form of research (Male, FGD Participant, 5).

His observation is consistent MoE (2011) information that states action research is participatory research and usually involves collaboration between researchers and the evidence collected is qualitative and meaningful to those involved.

\section{Quality Education}

Many of HDP Candidates, HDTs/HDLs, and Coordinators discussed that HDP training contribute a lot for quality education because it improves professional knowledge of the teacher and this in turn improve students' academic performance. As we know, student's academic achievement is one of the indicators of quality education. Thus, HDP training has its own influence on academic achievement of the learner. One of the participants of this study and HDL has supported this idea and explained how HDP training has impacted on students' performance:

We informally check whether HDP candidates implement the professional knowledge that they have acquired from HDP training. As they told us, they apply the pedagogical knowledge that they have gained from HDP training and their students' performance shown progress than before HDP training (Male, Interview Participant, 3).

From this information, one can say that HDP training contribute a lot to quality education, because it improves students learning and their academic performance.

\section{Major Challenges in HDP Training Conflict with Regular Work}

The major concern that participants had relates with the schedule of the HDP. The majority of HDP candidates stated that HDP training schedule conflicts with their regular work. They reported that HDP sessions are conducted two times in a week and took hours in each week. This relatively affects the regular work. They felt that the HDP module has inflexible schedule. For instance, candidates of health sciences are unable to attend the program/training. Since they have various field works, it is hardly possible for them to attend the training in existing schedule. The majority of HDP candidates thus suggested that the module should be flexible according to the needs of participants. This information echoes with Many teachers either do not find suitable professional development, or cannot attend because of conflicting work schedules (OECD, 2009). To be most effective, teachers' professional learning should be based upon an assessment of their specific learning needs and feedback about their teaching (GTE, 2005).

\section{Low Incentive}

Many participants in this study felt that the university provides low incentive for HDP Leaders, Coordinators, and HDP candidates. They reported that the incentive mechanism of our university is very low as compared to other universities like Dilla University, Wachamo University, and Gondar University. For example, according to HDLs and Coordinator information, the Wachemo University incentive for HDL is 18,000 ETB and use 6cr.hr for each candidate. But they reported that our university incentive for HDP Candidates, HDLs, and Coordinators is not that encouraging. The university use 3cr.hr for under loaded HDLs and $6 \mathrm{ch} . \mathrm{hr}$ for overloaded HDLs and $2 \mathrm{ch} . \mathrm{hr}$ for HDP candidates as an incentive. HDTs have no payment and HDP Coordinators' incentive is similar with Department head position allowance.

According to the first-hand information from HDLs and HDP Coordinator indicate that, Gondar University recruited foreign expert as HDP Coordinators and the salary is monthly based which is 30,000 ETB. They 
reported that the Ethiopian Federal Ministry Education $(\mathrm{MoE})$ has no clear structure regarding HDP training that governs all universities. Due to that reason, the Ethiopian public universities run this training program as they like. One essential component in fulfilling that imperative is the strategic allocation of human, financial, and time resources to guarantee that all teachers have access to high-quality professional development (Archibald et al., 2011).

\section{Low Support and Follow Up}

Many participants of this study discussed that there is a lack of support and follow up for the smooth running of the HDP training from the side of the university. Hoja (Male, FGD Participant 3) and HDL explains that:

The university is committed half-heartedly to run the program because there is a shortage of inputs such as stationery materials, suitable HDP training rooms, giving low credit for HDP graduates. Besides, there is a lack of support and follow up from side of the university.

The university action is contrary with Missouri Professional Learning Guidelines for Student Success (2013) posits that professional development programs should be supported by strong leadership and appropriate resources to the success of the program.

\section{Low Motivation from the Side of the HDP Candidates}

The majority of HDLs reported that HDP candidates have low motivation towards HDP training. Study participants discussed the indicator of their low motivation towards for the training from three directions/angles. First, the registration process for HDP training. The departments and colleges force the teachers to register in HDP in order to attend the HDP training. This implies that they have low motivation towards the HDP training. Second, high absentees and drop out of the training. Kanko (Male, interview Participant 3) has explained the problem of candidates' absenteeism and drop out from his group as follows: "Initially, we had more than forty candidates. But now we have only twenty-three candidates. Even from them, many candidates are referred to next the year". But according to HDP guideline, one candidate should attend $80 \%$ in each module. A trainee can only be absent for a maximum of two sessions.

According to participants, trainees' low is attributable to the low regard of the top management to HDP. They felt that they have a positive attitude towards the program, however, there is a poor commitment towards this training.

\section{Low Motivation and Lack of Experience from the Side of the HDLs/HDTs}

HDP Candidates discussed that HDLs are not highly motivated to treat the candidates due to lack of incentives. They reported that the incentive that the university gives for HDL is not attractive and encouraging for them to do more. The university allocates $3 \mathrm{cr} . \mathrm{hr}$ for under loaded leaders and $6 \mathrm{ch} . \mathrm{hr}$ for overloaded leaders as an incentive. On the other hand, HDP Candidates reported that some HDLs lack experience. They felt that the program demands professionals of pedagogy and experience related to the profession, because there are different complex theories of pedagogy those leaders from another field of the study unable to explain well. Study participants reported that for the last about seven years, the program was run by Institutional Quality Enhancement (IQE) Directorate Director, Office and they assign HDLs and HDP Coordinators from other field of study and the program faced a number of challenges.

However, in this year, there is some sort of improvement because now the HDP training has been run by the School of Pedagogical and Behavioral Sciences. Seid (Male, Interview Participant, 1), HDL and participant of this study have supported the above idea in an interview session by saying:

HDP training program demand the professional knowledge, skills and attitudes of pedagogy and a lot of preparation to train HDP candidates. As my first hand information from my colleagues, some HDLs simply read the topic and sub topic in the HDP session. However, HDP training encourages engaging candidates to work collaboratively in group work in order to share their experience with each other and to understand the concept of the issue raised.

\section{Low Regard from the side of the Departments}

The majority of HDP candidates discussed that many departments have low regard for this training program. And their low regard manifested in different ways. Some assign HDP candidates in the other department tasks in an HDP session day. Others force candidates to attend DC meetings, assign them as invigilator and participants in different committee tasks. It could be said department regard HDP training as a secondary issue.

\section{Low Value for HDP Certificate}

Majority of HDP Candidates, HDP Leaders as well as Coordinators said that there is no clear credit for HDP Certificate. They reported that the legislation of the university justified the HDP Certificate will carry 5\% in any position competition including scholarship. However, it is not still practical and there faculty who is rejected 
from competition due to lack of HDP certificate. Abate (Male Interview Participant 1), HDL and participant of this study says:

In our university, there are different positions being posted for academic staff members including scholarship position. But HDP Certificate is not considered as a minimum requirement in any competition that the university post. Hence, the value of HDP is not clear for candidates as well as HDLs.

From the above information, we can deduce that HDP certificate has low value for promotion as well as scholarship competition at Arba Minch University.

\section{CONCLUSIONS AND IMPLICATIONS}

\section{Conclusions}

Based on the above results and discussions, the following conclusions remarks made:

The HDP training can improve the professional knowledge of the teachers. It may enhance the teachers' skill in assessment methods, procedures of conducting action research, and ways of implementing active learning method in large class size, etc. Encouragingly, participants seem have a positive attitude towards HDP training.

The study also revealed that trainees in HDP have acquired necessary professional knowledge. They have developed necessary professional knowledge, skills and attitudes in the following major areas of instructional process: Instructional Phase, Collaborative Work, Reflection, and Action Research. On the other hand, HDP training contributes a lot for quality education because it improves professional knowledge of the teacher and this in turn improve students' academic performance.

On the other hand, from the study, we can notice that the program currently facing a number of challenges that affect the smooth running of the HDP training. The challenges emanated mainly from four directions/sides: the university, departments, HDP candidates, HDLs and Coordinators. From the side of the university, there is low incentive, lack of follow up and support and these challenges may impede the success of the program. In addition, HDLs, HDP Candidates as well as Coordinators have low motivation towards the program because of lack of follow up and support and low incentive from the side of the university. The university follows up and support is not encouraging as compared to other public universities. Besides, there is the low regard from the side of the department because the departments assign the teachers in various routine activities in the HDP session day. Finally, the value of HDP Certificate is unclear because there is low value of HDP Certificate.

\section{Implications for Educational Policy}

Improving the quality of education should undoubtedly be a focus of attention. Continuing professional development, such as in-service training is one of the most pressing of all the factors that affect quality of education (Bekalu, 2006). Study participants discussed that HDP training is important training for teachers in order to improve their professional knowledge. Hence, HDP Candidates have a positive attitude towards the HDP training. They believe that this training may enhance their instructional skill. However, HDP training is poorly coordinated and managed at Arba Minch University.

The Ethiopian Federal Ministry Education $(\mathrm{MoE})$ has no clear structure regarding HDP training that governs all universities. Due to that reason, the Ethiopian public universities run this training program as they like. Some universities incentive, follow up and support for the program is encouraging. In this study, HDP candidates, HDLs, HDTs, and Coordinators throughout the interview as well as FGD session stressed that the Arba Minch University incentive, follow up and support is not encouraging. As a result, HDP Candidates, HDLs, HDTs, and Coordinators have lack of motivation towards the trainings. Therefore, it is better to consider/revisit the incentive mechanism that the university currently applying. Furthermore, the support and follow up to the success of the program should be improved. The professional development program requires systematic support and process to evaluate its effectiveness since it affects the excellence and standard of advance career (Boonmak et.al, 2015).

\section{Implications for Future Research}

The HDP Training is one of a professional development program that aimed to improve quality Ethiopian higher education. In this study, teachers' perception towards HDP training was ascertained. But the study merely assessed teachers' perception towards the training, but not its impact on students' performance. In addition, the study didn't not investigate the role of university academic management body commitment towards the success of this training program. Therefore, future researchers and scholars can conduct further study on HDP training and its impact on students' academic performance to better understand the positive impact of this training program on quality education in general and students' academic performance in particular. In addition, future researchers and scholars can conduct their study in the role of the university academic management body for the success of this training program to better understand their commitment towards the success of the program. 


\section{REFERENCES}

Adula, Bekele. (2008). Application of Higher Diploma Program training skills in classroom instruction: The case of Education Faculty, Jimma University (Ethiopia), Ethiop. J. Educ. \& Sc. Vol. 4 No. 1.

Bhattacherjee, A. (2012). Social Science Research: Principles, Methods, and Practices (2nd ed.), University of South Florida Tampa, Florida, USA.

Archibald, S. et al. (2011). High-Quality Professional Development for All Teachers: Effectively Allocating Resources, National Comprehensive Center For Teacher Quality.

Bekalu, Atnafu. (2006). Reflections on Higher Diploma Program (HDP): The Case of St. Mary's University College, Proceedings of the Fourth National Conference on Private Higher Education in Ethiopia, available at https://www.smuc.edu.et/index.php/ research-publication/annual-national-conference-onpheis?dow.

Benes, et al. (2016).Teachers' Perceptions of Using Movement in the Classroom, Vol. 73. 110-135 2016 , available at http://dx.doi.org/10.18666/TPE-2016-V73-I1-5316, Boston University.

Boonmak, T. et al. (2015). The Ultimate Impacts for Thai Teachers: Teachers Development System in Learning Management, International Education Studies; Vol. 8, No. 12, Canadian Center of Science and Education.

Corbetta, P. (2003). Social Research Theory, Methods and Techniques, London Thousand, Oaks New Delhi, SAGE Publications

Creswell, J. (2012). Educational Research: Planning, Conducting, and Evaluating Quantitative and Qualitative Research (4th ed.), University of Nebraska-Lincoln.

Demewoz Admasu. (2016). Effectiveness of Higher Diploma Program for early care academics in Ethiopia, Journal of Studies in Higher Education, Volume 41,pp.1741-1753, available at http://tandfonline.com/doi/pdf/10.1080/03075079.2016.1221652.

Federal Democratic Republic Government of Ethiopia. (1994). New Education and Training Policy, Addis Ababa, Ethiopia.

Gill, P. et.al. (2008). Methods of Data Collection in Qualitative Research: Interviews and Focus Groups, British Dental Journal, Volume 204, No. 6

Hardy, I. (2016). Teacher Professional Development: A Sociological Study of Senior Educators' PD Priorities in Ontario, Canadian Journal of Education, Vol. 32, No. 3.

Hayes, M. (2010). Why Professional Development Matters. USA: Learning Forward, Unpublisehd Research Material.

Hennink, M. (2007). International Focus Group Research A Handbook for the Health and Social Sciences, Published in the United States of America by Cambridge University Press, New York.

Hill, H. (2009). Fixing Teacher Professional Development, Harvard Graduate School of Education, Cambridge, Massachusetts.

Hirsh, S. (2014). Building Professional Development to Support New Student Assessment Systems, Unpublished Research Material.

Mack, N. (2005). Qualitative Research Methods: a Data Collector's Field Guide, Family Health International.

Ministry of Education. (2003). Higher Diploma Programme for Teacher Educators, Handbook Addis Ababa, Ethiopia.

Ministry of Education. (2005). Education Sector Development Program III (ESDP-III), Addis Ababa, Ethiopia.

Ministry of Education. (2005). Education Sector Development Program V (ESDP-V), Addis Ababa, Ethiopia.

Ministry of Education. (2010). School Improvement Program Guidelines: Improving the quality of education and student results for all children at primary and secondary schools, Addis Ababa, Ethiopia.

Ministry of Education. (2011). Higher Diploma Program for Teacher Educators Handbook, Addis Ababa, Ethiopia.

Ministry of Education. (2011). Higher Diploma Programme for Teacher Educators, Higher Diploma Program Guidance, Addis Ababa, Ethiopia.

. (2013). Missouri Professional Learning Guidelines for Student Success Missouri Department of Elementary and Secondary Education, Unpublished Document.

OECD. (2009). The Professional Development of Teachers: Creating Effective Teaching and Learning Environments: First Results from TALIS.

Reading First Program. (2005). Why Is Professional Development So Important? The Newsletter for the Reading First Program.

Sherman, R. et al. (2003). Evaluating Professional Development Resources: Selection and Development Criteria, American Institutes for Research.

Tate, M. L. (2009). Workshops: Extend learning beyond your presentation with these brain friendly strategies, Journal of Staff Development, 30 (1), 44-46.

UNESCO. (2007). Teaching and Learning in Higher Education in Africa, Vol.9 No.1, News Letter.

Walters, K. (2016), Professional Development to Support Teachers of Struggling Algebra I Students, American 
Institutes for Research.

Yilfashewa, Seyoum. (2011). Invigorating Quality through Professional Development Programs in Ethiopian Higher Education Institutions: Implications for Curriculum Enactment at Haramaya University, International Journal of Social Sciences and Education, Volume,1.

Yilfashewa, Seyoum. (2016). Analysis of Faculty Members Attitude towards Academic Development Endeavors in Some Selected Ethiopian Universities, International Journal of Instruction, Vol.9, No.1. 